Original Research Paper

\title{
Design of Intelligent Household Fruit Vinegar Fermentation Device and Optimization of Key Parameters
}

\author{
${ }^{1}$ Xinpeng Dai, ${ }^{1}$ Xiaoxue Xing, ${ }^{1}$ Lin Liu, \\ ${ }^{1}$ Zhili Xu, ${ }^{1,2}$ Jianfeng Sun, ${ }^{1,2}$ Jie Wang and ${ }^{1,2}$ Jianlou Mu \\ ${ }^{I}$ College of Food Science and Technology, Hebei Agricultural University, Baoding 071000, China \\ ${ }^{2}$ Engineering Technology Research Center for Processing of Agricultural Products of Hebei Province, Baoding, China
}

Article history

Received: 29-06-2018

Revised: 02-08-2018

Accepted: 17-08-2018

Corresponding Author:

Jianfeng Sun

College of Food Science and

Technology, Hebei Agricultural

University, Baoding 071000 ,

China

Email: causunjf@126.com causunjf@hebau.edu.cn

\begin{abstract}
Compared with carbonated beverages, fruit vinegar was gradually becoming more favored by consumers, because of their higher nutritional functions. But its popularization was limited by higher selling price. This article described a fruit vinegar fermentation device that can be used at home and also introduced the design principles, composition and operation methods. Furthermore, taking apple vinegar as an example, the key parameters of fermentation were determined by single-factor and orthogonal tests. In alcohol fermentation, the fermentation time, fermentation temperature and inoculation amount were $72 \mathrm{~h}, 30^{\circ} \mathrm{C}$ and $0.07 \%$, respectively. In acetic acid fermentation, the fermentation temperature, ventilation and bacteria amount were $32^{\circ} \mathrm{C}, 4 \mathrm{~L} / \mathrm{min}$ and $0.18 \%$, respectively. The refreshing and fermented apple vinegar could be obtained with the total acid content of $3.6 \mathrm{~g} / 100 \mathrm{~mL}$. The kinetic formula between the content of acetic acid and fermentation time was calculated and acetic acid content of fruit vinegar could be determined by controlling fermentation time according to the formula. So, the device could produce different content of acetic acid of fruit vinegar automatically, without manual operation. The study was sufficient to provide reference and experience for further popularization of fruit vinegar.
\end{abstract}

Keywords: Fruit Vinegar, Intelligent Household Electrical Appliance, Liquid Fermentation, Fermentation Kinetics

\section{Introduction}

Fruit vinegar is a type of acidic beverage or condiment made from fruit (such as apples, jujubes, bananas, pears and watermelons) by using microbial fermentation technology (Marques et al., 2010). Fruit vinegar possesses a variety of physiological functions, such as antibacteria, anti-infection, antioxidation, blood glucose control, lipid metabolism regulation, weight loss and anticancer activities (Bouazza et al., 2016; Shahidi et al., 2008). Grain vinegar is the main condiment vinegar due to traditional eating habits, whereas fruit vinegar is recognized as the beverage in China generally. In the past five years, the consumption scale of apple vinegar of China had been increasing gradually, with a compound average annual growth rate of $10.74 \%$ (CIIN, 2016). The market of fruit vinegar had been expanding. However, fruit vinegar was sold as commodity with a few fruit varieties. Most of them are blended with water and acetic acid, not the real brewing apple vinegar (Patzold et al., 2005; Kocher et al., 2007). Moreover, the high selling price limits its development to form a long-term drinking habit for consumer. Homemade fruit vinegar is not yet popular at home because of its limited conditions, such as long fermentation period and poor taste. At present, the multifunctional enzyme machine sold on the market can produce fruit vinegar. But in this way, commercial vinegar was poured into fruit juice before fermentation and then undergoes anaerobic fermentation. The sour actually did come from lactic acid bacteria by anaerobic fermentation not from acetic acid bacteria by aerobic fermentation. So, there was no suitable device to produced fruit vinegar at home.

In this study, an intelligent fermentation device used at home was created. A variety of fruits, such as apples, pears, watermelons and other fruits with little or no pectin can be transformed into fruit vinegar by the 
device. The parameters of alcohol and acetic acid fermentation were optimized. A fitting curve was established between fermentation time and total acid content of fruit vinegar. It can provide a mathematical model for the fermentation device to automatically control the fermentation time to produce different total acid content of the fruit vinegar.

\section{Materials and Methods}

\section{Device Design and Implementation}

Vinegar fermentation includes alcoholic fermentation and acetic acid fermentation. The former is anaerobic fermentation and the latter is aerobic fermentation. Therefore, the fermentation temperature and the dissolved oxygen in the fermentation broth are important factors in fermentation process. As shown in Fig. 1, the fermentation device is provided with an oxygen supply device, which is composed of an electromagnetic inflator (8), a gas purifier (7) and a gas supply tube (5). During acetic acid fermentation, the control system adjusts the input gas rate and time according to the parameters coded into it. The device is also provided with a temperature control device that consists of a positive temperature coefficient heater (13) and a polyurethane foam insulation layer (11). During the fermentation of alcohol and acetic acid, the control system adjusts the temperature of the fermentation broth at different fermentation stages according to the parameters coded into it. The fermented broth is in a special bottle (18), which is filled with pumice (22) in the bottom of the fermenter bottle. Air is imported through the air pipe and then is crushed into small bubbles by pumice, which is beneficial to enhance the solubility of oxygen in fermentation broth. $\mathrm{CO}_{2}$ is continuously produced in alcohol fermentation and the air in the acetic acid fermentation stage is continuously fed into the fermenter. To maintain the balance of air pressure of inside and outside of the device, an air outlet hole is designed on the flip cover, which is composed of a oneway vent valve (2) and a gas filter (3). The one-way vent valve prevents external air from entering the fermenter and destroying the anaerobic environment during alcohol fermentation. The gas filter can absorb the effluent gas to make the fruit vinegar suitable for using at home. A kinetic mode of acetic acid fermentation was input the system of fruit vinegar fermentation device. When users input certain value of content of acetic acid, the device could adjust the fermentation time according to the system automatically. In this way, the device could produce different acidity of fruit vinegar.

\section{Operation Flow}

The fermentation vessel must be sterilized first before using the fermentation device to make fruit vinegar. After the vessel is dried, freshly squeezed juice was poured into it and then a certain percentage of activated yeast was inoculated. Then, the fermentation device started to work. All parameters were set for alcohol and acetic acid fermentation. After acetic acid fermentation, the fermentation device will automatically stop working and a ring will sound. The brewed vinegar was approximately $1.5 \mathrm{~L}$ and $22.5 \mathrm{~g}$ of salt must be mixed into the broth. The fruit vinegar could not be drunk until 7 days later.

\section{Materials and Reagent}

Apples, malus pumila mill and sucrose were purchased in the local market, Baoding, China. Yeast (brewer active yeast, Angel Yeast Co., Ltd.), acetobacter (Shanghai Brewing 1.01, Shanghai Jiamin Brewing Food Co., Ltd.) and sodium hydroxide (Sinopharm Group Chemical Reagent Co., Ltd.) were purchased from reagent companies of China.
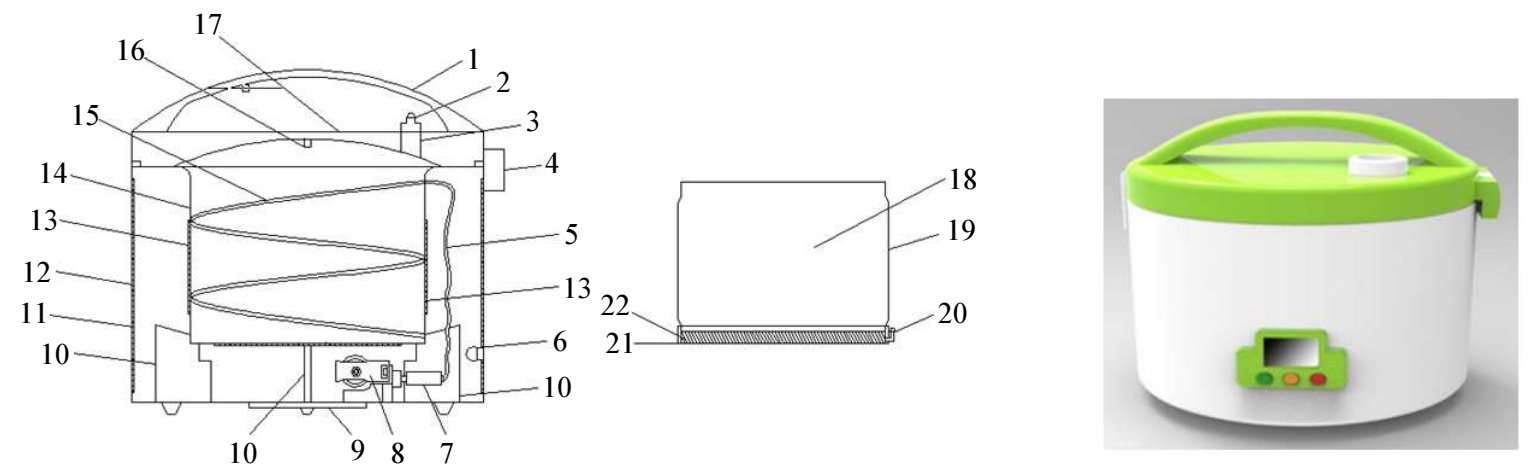

Fig. 1: Fermentation device with fruits; 1. Handle 2. Check valve 3. Air filter 4. Connecting shaft 5. Air inlet pipe 6. Ultraviolet disinfection lamp 7. Gas purifier 8. Electromagnetic air pump 9. Air inlet 10. Support structure 11. Insulating layer 12. Outer shell 13. Positive temperature coefficient heating plate 14. Inner shell 15. Air inlet pipe 16. Temperature sensor 17. Cover 18. Fermentation vessel 19. Fermentation flask 20. Port 21. Cover 22. Pumice 
Fruit vinegar fermenters were made by ourselves. Alcoholmeter (division value is $0.1^{\circ}$, Hebei Wuqiang Tonghui Instrument Factory), PHS-25Ph meter (Shanghai Lei Magnetic Company), FA2004 electronic balance (Beijing Satoli Instrument Co., Ltd.), electroheating constant temperature cultivator (Beijing Changfeng Instruments Co., Ltd.) and portable digital refractometer (Bell Analysis Instrument Co., Ltd.) were used to test experiment parameters.

\section{Process Flow and Operating Key Points}

The process flow was as follows: Apple $\rightarrow$ cleaning $\rightarrow$ removing cores $\rightarrow$ juicing $\rightarrow$ boil sterilization $\rightarrow$ adjusting soluble solid content $\rightarrow$ inoculating yeast $\rightarrow$ alcoholic fermentation $\rightarrow$ inoculating acetic acid bacteria $\rightarrow$ acetic fermentation $\rightarrow$ sterilization $\rightarrow$ storage.

The key points of operating were as follows: Fresh apples with no damage were picked, washed and the cores were removed. $1 \mathrm{~L}$ apple juice should be extracted. The apple juice was then mixed with $1 \mathrm{~L}$ water, boiled for $5 \mathrm{~min}$ and cooled to $30^{\circ} \mathrm{C}$. The content of soluble solids reached $16^{\circ}$ Brix by adding sucrose. The fermentation device started to work after adding yeast. After the alcoholic fermentation completed, the acetic acid fermentation started and acetic acid bacteria was added into the vessel. Alcohol and total acid content must be measured according to the experimental design during fermentation.

Angel active dry yeast was taken into syrup of $2 \%$ at $35^{\circ} \mathrm{C}$ to rehydrate for $30 \mathrm{~min}$ until quantities of bubble produced. Acetic acid bacteria was taken into the fruit wine at $34^{\circ} \mathrm{C}$ to rehydrate for $30 \mathrm{~min}$.

\section{Single-factor Experiment of Alcohol Fermentation of Apple Juice}

\section{Effect of Fermentation Time on Alcohol Fermentation}

$2 \mathrm{~L}$ of fruit juice was used as fermentation broth. A mixture of $0.05 \%$ of the activated yeast was kept at a temperature of $30^{\circ} \mathrm{C}$. The value of alcohol content was measured at 12, 24, 36, 48, 60 and $72 \mathrm{~h}$, respectively. The test was repeated 3 times.

\section{Effect of Fermentation Temperature on Alcohol Fermentation}

$2 \mathrm{~L}$ of fruit juice was used as fermentation broth. A mixture of $0.05 \%$ of the activated yeast was kept at a temperature of $24^{\circ} \mathrm{C}, 26^{\circ} \mathrm{C}, 28^{\circ} \mathrm{C}, 30^{\circ} \mathrm{C}$ and $32^{\circ} \mathrm{C}$, respectively. The value of alcohol content was measured at $60 \mathrm{~h}$. The test was repeated 3 times.

\section{Effect of Inoculum Size on Alcohol Fermentation}

$2 \mathrm{~L}$ of fruit juice was used as fermentation broth. A mixture of $0.03 \%, 0.05 \%, 0.07 \%, 0.09 \%$ and $0.11 \%$ of the activated yeast was kept at a temperature of $30^{\circ} \mathrm{C}$, respectively. The value of alcohol content was measured at $60 \mathrm{~h}$. The test was repeated 3 times.

\section{Orthogonal Test of Alcohol Fermentation}

On the basis of a single-factor test, in accordance with orthogonal experimental design, we selected the fermentation time, fermentation temperature and inoculum size as the effect factors and alcohol content as evaluation value. The three-factor and three-level $\mathrm{L}_{9}\left(3^{4}\right)$ experiment (Table 1) was designed to optimize fermentation technology.

\section{Single-Factor Test of Acetic Fermentation on Apple Wine}

The apple juice was fermented with the optimized fermentation process parameters. After that, apple wine with an alcohol content of $7.6 \mathrm{~g} / 100 \mathrm{~mL}$ was obtained.

\section{Effect of Fermentation Temperature on Acetic Acid Fermentation}

A mixture of $0.14 \%$ of the activated acetic acid bacteria was kept at a temperature of $28^{\circ} \mathrm{C}, 30^{\circ} \mathrm{C}, 32^{\circ} \mathrm{C}$ and $34^{\circ} \mathrm{C}$, respectively, based on the fruit wine. Setup the Ventilation $4 \mathrm{~L} / \mathrm{min}$. The value of total acid content was measured at $6 \mathrm{~h}, 12 \mathrm{~h}, 18 \mathrm{~h}, 24 \mathrm{~h}, 30 \mathrm{~h}, 36 \mathrm{~h}, 42 \mathrm{~h}, 48 \mathrm{~h}, 54$ $\mathrm{h}$ and $60 \mathrm{~h}$, respectively. The test was repeated 3 times.

\section{Effect of Inoculation Size on Acetic Acid Fermentation}

A mixture of $0.06 \%, 0.10 \%, 0.14 \%$ and $0.18 \%$ of the activated acetic acid bacteria was kept at a temperature of $32^{\circ} \mathrm{C}$, respectively, based on the fruit wine. Setup the Ventilation $4 \mathrm{~L} / \mathrm{min}$. The value of total acid content was measured at 6 h, 12 h, 18 h, 24 h, 30 h, 36 h, 42 h, 48 h, $54 \mathrm{~h}, 60 \mathrm{~h}$, respectively. The test was repeated 3 times.

\section{Effect of Ventilation Rate on Acetic Acid Fermentation}

A mixture of $0.18 \%$ of the activated acetic acid bacteria was kept at a temperature of $32^{\circ} \mathrm{C}$, based on fruit wine. Setup the Ventilation $1 \mathrm{~L} / \mathrm{min}, 2 \mathrm{~L} / \mathrm{min}, 3 \mathrm{~L} / \mathrm{min}, 4 \mathrm{~L} / \mathrm{min}$ and $5 \mathrm{~L} / \mathrm{min}$, respectively. The value of total acid content was measured at $6 \mathrm{~h}, 12 \mathrm{~h}, 18 \mathrm{~h}, 24 \mathrm{~h}, 30 \mathrm{~h}, 36 \mathrm{~h}, 42 \mathrm{~h}, 48 \mathrm{~h}$, $54 \mathrm{~h}, 60 \mathrm{~h}$, respectively. The test was repeated 3 times.

Table 1: Orthogonal factors and levels of alcoholic fermentation

\begin{tabular}{llll}
\hline & Table 1: Orthogonal factors and levels of alcoholic fermentation & \\
\hline & Factor & & B Fermentation Time $\left({ }^{\circ} \mathrm{C}\right)$ \\
Level & A Fermentation Time $(\mathrm{h})$ & 28 & C Inoculation Size $(\%)$ \\
\hline 1 & 48 & 30 & 0.05 \\
2 & 60 & 32 & 0.07 \\
3 & 72 & 0.09 \\
\hline
\end{tabular}


Table 2: Orthogonal factors and levels of acetic acid fermentation

\begin{tabular}{llll}
\hline & Factor & & \\
Level & A Fermentation Temperature $\left({ }^{\circ} \mathrm{C}\right)$ & B Ventilation Rate $(\mathrm{L} / \mathrm{min})$ & C Inoculation Size $(\%)$ \\
\hline 1 & 30 & 3 & 0.14 \\
2 & 32 & 4 & 0.18 \\
3 & 34 & 5 & 0.22 \\
\hline
\end{tabular}

\section{Orthogonal Test of Acetic Acid Fermentation}

On the basis of a single-factor test, in accordance with orthogonal experimental design, we selected the fermentation temperature, inoculum size and ventilation rate as the effect factors and total acid content as evaluation value. The three-factor and three-level $\mathrm{L}_{9}\left(3^{4}\right)$ experiment (Table 2) was designed to optimize fermentation technology.

\section{Kinetic Model for the Production of Apple Vinegar Fermentation Product}

The quantitative curve of fermentation time and total acid content can be obtained by using the kinetic curve of acetic acid fermentation (Garrido-Vidal et al., 2003; Infantes et al., 2012). Fruit vinegar with different tota acid content could be obtained by adjusting the fermentation time. The growth of acetic acid bacteria is directly related to the production of total acid content and belongs to the coupling type. The growth curve of acetic acid bacteria is S-type. Thus, the logistic and Boltzmann model can be used. The equation with a large degree of fit $\mathrm{R}^{2}$ could be used for prediction (Gonzalez-Saiz and Pizarro, 2003).

The fitting curve of fermentation time and total acid during fermentation was measured according to the optimized parameters as followed: In alcohol fermentation, the fermentation time, fermentation temperature and inoculum size were $72 \mathrm{~h}, 30^{\circ} \mathrm{C}$ and $0.07 \%$, respectively; in acetic fermentation, the fermentation temperature, ventilation rate and inoculum size were $32^{\circ} \mathrm{C}, 4 \mathrm{~L} / \mathrm{min}$ and $0.18 \%$, respectively.

\section{Measurement Indicators and Methods}

The soluble solid was measured by digital refractometer; Alcohol content was measured by distillation method accordance to GB/T 15038-2006; Total acid content was measured by $\mathrm{NaOH}$ titration method according to GB/T 5009.41-2003. All data sets were analyzed statistically by SPSS 17.0 and all figures were made by Origin8.6.

\section{Results and Discussion}

\section{Single-factor Test Results of Alcohol Fermentation} of Apple Juice

\section{Effect of Fermentation Time on Alcohol Fermentation}

Figure $2 \mathrm{a}$ showed that the growth rate of ethanol was rapid between $12 \mathrm{~h}$ and $36 \mathrm{~h}$. During this period, a large amount of soluble sugar was converted into ethanol by yeasts (Jin et al., 2015). The growth rate of ethanol was slow at $36 \mathrm{~h}$. The content of alcohol reached the max value of $7.2 \mathrm{~g} / 100 \mathrm{~mL}$ at $60 \mathrm{~h}$ first and maintained steady. Therefore, $60 \mathrm{~h}$ was better as alcohol fermentation time.

\section{Effect of Fermentation Temperature on Alcohol Fermentation}

Figure $2 \mathrm{~b}$ showed that the content of alcohol increased gradually with the growth fermentation temperature from $24^{\circ} \mathrm{C}$ to $30^{\circ} \mathrm{C}$ in $60 \mathrm{~h}$, which could be explained that higher temperature made the metabolism yeast more active. When the temperature was $30^{\circ} \mathrm{C}$, the highest alcohol content reached $7.2 \mathrm{~g} / 100 \mathrm{~mL}$. But, too high temperature led to low alcohol content. This condition could be explained that high temperature led to premature aging of the yeast and shortened the conversion rate of alcohol (Pramanik et al., 2003; Torija et al., 2003).

\section{Effect of Inoculation Size on Alcohol Fermentation}

Figure 2c showed the highest alcohol content was observed at inoculum size of $0.2 \%$ (that is, $0.2 \mathrm{~g} / 100 \mathrm{~mL}$ ). But, too high inoculation size led to low alcohol content. This could be demonstrated that an excessive amount of yeast used more sugar to meet the growth and reproduction of themselves. Thereby less sugar was converted into alcohol (Schmidt, 2005). Moreover, the excessive amount of yeast in the fermentation broth could enhance the taste of the yeast, which destroyed the original flavor of apple wine.

\section{Orthogonal Test of Alcohol Fermentation}

As shown in Table 3, the primary and secondary factors affecting the apple wine fermentation are ranked as $\mathrm{A}>\mathrm{B}>\mathrm{C}$, that meant, fermentation time $>$ fermentation temperature $>$ inoculation amount. The optimal process parameter was $\mathrm{A}_{3} \mathrm{~B}_{2} \mathrm{C}_{2}$. The optimum process condition for this experiment was fermentation for $72 \mathrm{~h}$, temperature $30^{\circ} \mathrm{C}$ and the inoculation size of yeast $0.07 \%$. The verification test showed that the content of alcohol in apple wine reached 7.6\%.

\section{Single-factor Test Results of Acetic Acid Fermentation Effect of Fermentation Temperature on Acetic Acid
Fermentation}

Figure $2 \mathrm{~d}$ showed that $32^{\circ} \mathrm{C}$ was the optimum temperature for acetic acid fermentation in this experiment. The maximum content of total acid reached $3.5 \mathrm{~g} / 100 \mathrm{~mL}$. Higher temperature $34^{\circ} \mathrm{C}$ led to accelerate 
aging of acetic acid bacteria, which resulted in the reduction of fruit vinegar yield (Woo et al., 2014). When the temperature was $28^{\circ} \mathrm{C}$ or $30^{\circ} \mathrm{C}$, the growth and

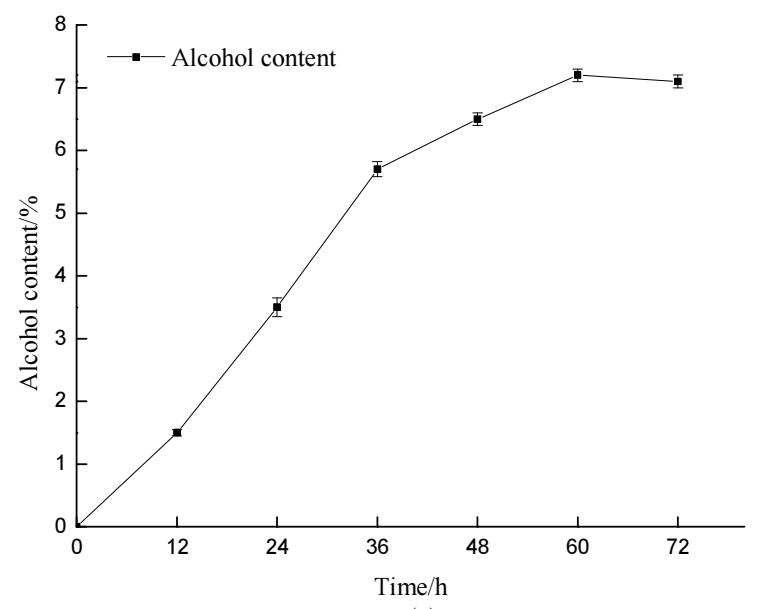

(a)

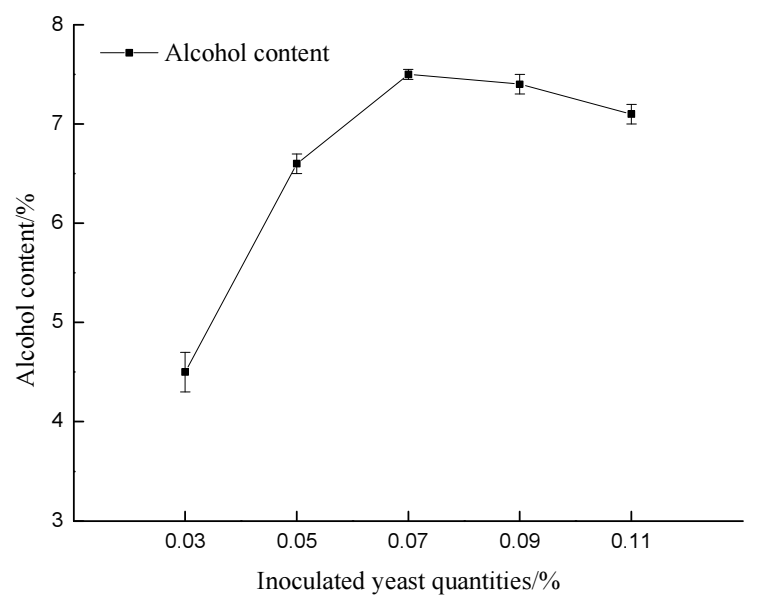

(c)

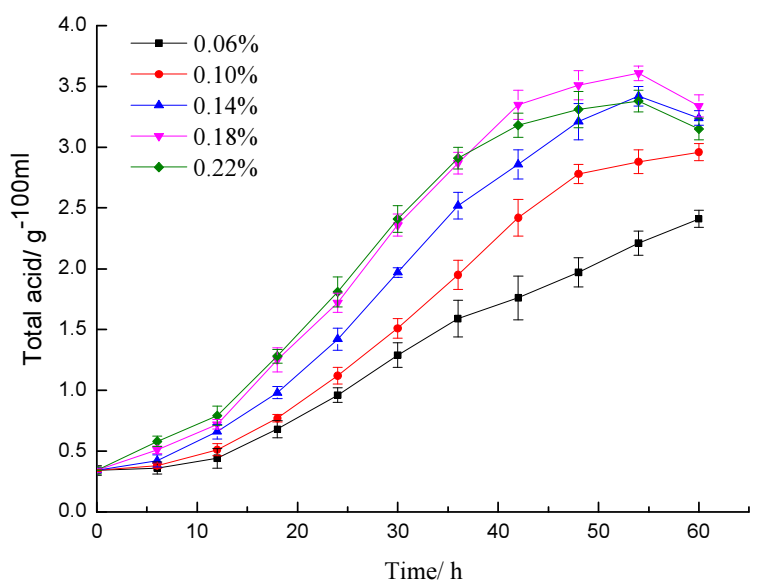

(e) metabolism of microorganisms were inactive and the fermentation period was longer, which resulted in excessive volatilization of alcohol.

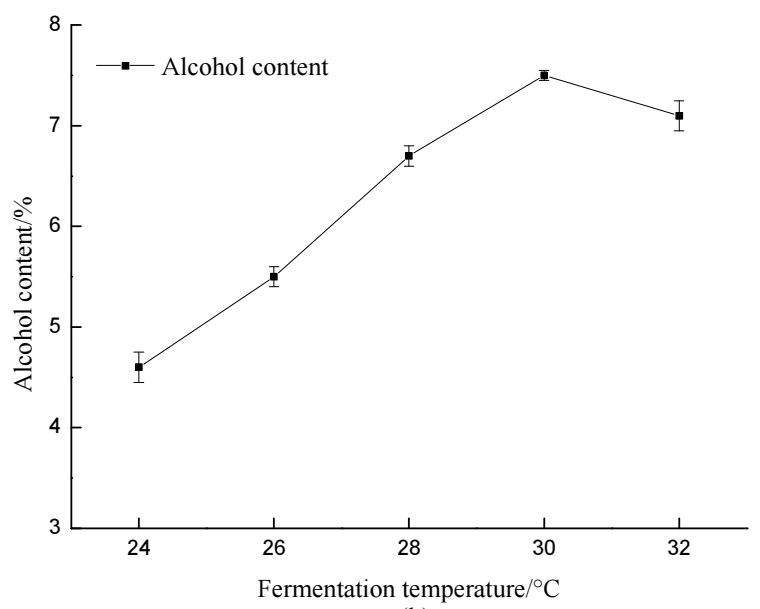

(b)

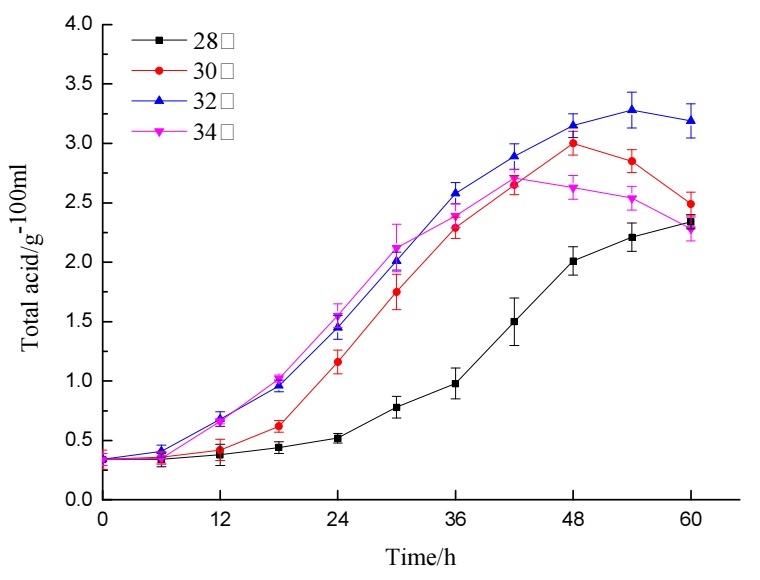

(d)

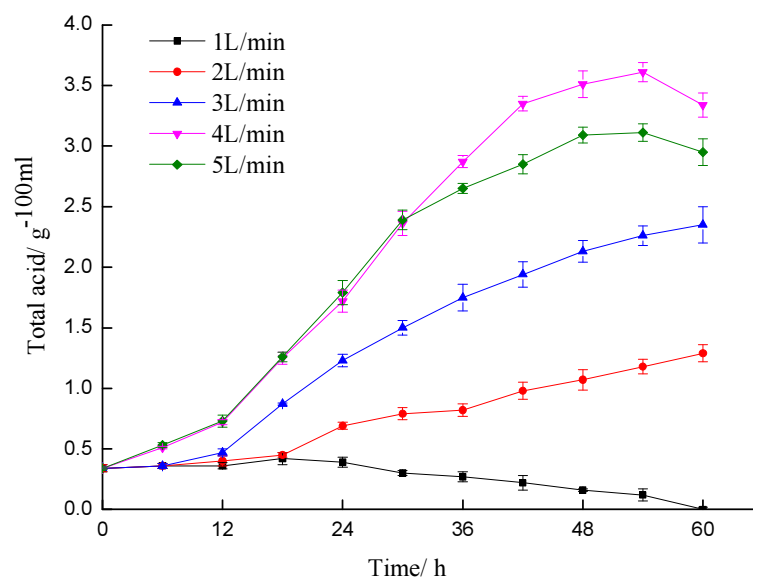

(f)

Fig. 2: Effect of different fermentation parameters on alcohol content and total acid content during alcohol fermentation and acetic acid fermentation. Alcohol fermentation: a-time; b-fermentation temperature; c-inoculum size. Acetic acid fermentation: dfermentation temperature; e-inoculum size; f-ventilation rate 
Table 3: Orthogonal test results of alcohol fermentation

\begin{tabular}{lllll}
\hline Test number & $\begin{array}{l}\text { A Fermentation } \\
\text { time }(\mathrm{h})\end{array}$ & $\begin{array}{l}\text { B Fermentation } \\
\text { temperature }\left({ }^{\circ} \mathrm{C}\right)\end{array}$ & $\begin{array}{l}\text { C Inoculation } \\
\text { Amount }(\%)\end{array}$ & Alcohol content $(\%)$ \\
\hline 1 & $1(48)$ & $1(28)$ & $1(0.05)$ & 4.5 \\
2 & 1 & $2(30)$ & $2(0.07)$ & 6.6 \\
3 & 1 & $3(32)$ & $3(0.09)$ & 6.1 \\
4 & $2(60)$ & 1 & 2 & 7.0 \\
5 & 2 & 2 & 3 & 7.1 \\
6 & 2 & 3 & 1 & 7.7 \\
7 & $3(72)$ & 1 & 3 & 7.2 \\
8 & 3 & 2 & 1 & 7.0 \\
9 & 3 & 3 & 2 & \\
$\mathrm{k}_{1}$ & 17.2 & 18.6 & 18.4 & \\
$\mathrm{k}_{2}$ & 20.8 & 20.9 & 20.6 & \\
$\mathrm{k}_{2}$ & 21.3 & 19.8 & 20.3 & \\
$\mathrm{R}$ & 4.1 & 2.3 & 2.2 & \\
\hline
\end{tabular}

Effect of Inoculated Size on Acetic Acid Fermentation of Cider

As shown in Fig. 2e, there was a lower conversion rate of ethanol, when the size of acetic acid bacteria was small. That could be explained that the low inoculation size extended the fermentation period, which resulted in excessive volatilization of alcohol. The growth curves of total acid were similar in the early stage of fermentation at $0.18 \%$ or $0.22 \%$ of the inoculated size of acetic acid bacteria. However there was a lower content of acetic acid with $0.22 \%$ inoculated size, which could be explained that more alcohol was consumed for growth and reproduction, not for producing acetic acid (Gomez and Cantero, 1998; $\mathrm{Wu}$ et al., 2016). It was obvious that the maximum acidity reached $3.61 \mathrm{~g} / 100 \mathrm{~mL}$ with the least fermentation time, when the inoculated size was $0.18 \%$.

Effect of Ventilation Rate on Acetic Acid Fermentation

Acetic acid fermentation required oxygen to oxidize ethanol and produce acetic acid. Increasing the amount of dissolved oxygen is one of the most important procedures in acetic acid fermentation. As shown in Fig. 2f, when the ventilation rate was less than $3 \mathrm{~L} / \mathrm{min}$, the curves of total acid content were not S-type (Gomez and Cantero, 1998; Gullo et al., 2014). In other words, when the ventilation rate was higher than $3 \mathrm{~L} / \mathrm{min}$, the growth of acetic acid bacteria was normal. When the ventilation size was $4 \mathrm{~L} / \mathrm{min}$ or 5 $\mathrm{L} / \mathrm{min}$, the acetic acid growth curve was relatively consistent in the early stage and belonged to the S-type. However, in the later stage, the excessive ventilation size of $5 \mathrm{~L} / \mathrm{min}$ evaporated more alcohol and acetic acid. Thus, the maximum content of acetic acid was less than that of $4 \mathrm{~L} / \mathrm{min}$ in the test group.

In the acetic fermentation single-factor test, the optimal curves had tendency of ascending first and descending in succession. The reasons were: The acetic acid was excessively oxidized by the acetic acid bacteria and the other was that the rate of acetic acid formation was less than its rate of volatilization (Jimenez-Hornero et al., 2009).

The initial fermentation alcohol content is $7.6 \%$. Thus, the content of $9.9 \mathrm{~g} / 100 \mathrm{~mL}$ total acid could be obtained theoretically. However, special ventilation form and the small proportion of the fermentation vessel diameter and height caused some of the alcohol and volatile acid evaporating. Thus, the final total acid content only reached $3.6 \mathrm{~g} / 100 \mathrm{~mL}$.

\section{Orthogonal Test of Acetic Acid Fermentation}

As shown in Table 4, the primary and secondary factors affecting the acetic fermentation of apple wine were ranked as $\mathrm{B}>\mathrm{A}>\mathrm{C}$. That meant, ventilation rate $>$ fermentation temperature $>$ inoculation size. The optimal process was $\mathrm{A}_{2} \mathrm{~B}_{2} \mathrm{C}_{2}$. The optimum process condition for this experiment was fermentation $32^{\circ} \mathrm{C}$, ventilation rate $4 \mathrm{~L} / \mathrm{min}$ and the inoculation size of acetic acid bacteria $0.18 \%$. The verification test showed that the total acid of apple vinegar reached $3.65 \mathrm{~g} / 100 \mathrm{~mL}$.

\section{Kinetic Model for the Production of Apple Vinegar}

\section{Fermentation Product}

Table 5 showed the logistic and Boltzmann fitting results. The logistic fitting result was better with $\mathrm{R}^{2}=$ 0.99925 . In the validation test, the measured values and fitting curves were relatively consistent. This result showed that the model could be used to predict the content of total acid of fruit vinegar. As shown in Fig. 3, the total fermentation time was $54 \mathrm{~h}$. Because oxygen was injected at bottom of the fermentation vessel, the amount of acetic acid volatilization was relatively high under this condition. The acetic acid fermentation time of $54 \mathrm{~h}$ could be used to minimize the loss of the product. The fitting curve between 
fermentation time and total acid content of fruit vinegar can be used to control fermentation automatically. It was edited into the automatic control system of the device. Users can input any Y, total acid content (less than $3.5 \mathrm{mg} / 100 \mathrm{~mL}$ ), into the system of fruit vinegar fermentation device. According to the fitting curve, system can calculate the only $\mathrm{X}$ (fermentation time). Thus the device can produce different total acid content by adjusting fermentation time. Of course, this fitting curve was just suitable for making apple vinegar. More fitting curves should be studied to produce other fruit vinegar.

Table 4: Orthogonal test results of acetic acid fermentation

\begin{tabular}{lllll}
\hline Test number & $\begin{array}{l}\text { A Fermentation } \\
\text { temperature }\left({ }^{\circ} \mathrm{C}\right)\end{array}$ & $\begin{array}{l}\text { B Ventilation } \\
\text { Rate }(\mathrm{L} / \mathrm{min})\end{array}$ & $\begin{array}{l}\text { C Bacteria } \\
\text { amount }(\%)\end{array}$ & Acid value $(\%)$ \\
\hline 1 & $1(30)$ & $1(3)$ & $1(0.14)$ & 1.82 \\
2 & 1 & $2(4)$ & $2(0.18)$ & 2.96 \\
3 & 1 & $3(5)$ & $3(0.22)$ & 2.53 \\
4 & $2(32)$ & 1 & 2 & 2.43 \\
5 & 2 & 2 & 3 & 3.48 \\
6 & 2 & 3 & 1 & 2.14 \\
7 & $3(34)$ & 1 & 3 & 2.08 \\
8 & 3 & 2 & 1 & 2.90 \\
9 & 3 & 3 & 2 & \\
$\mathrm{k}_{1}$ & 7.31 & 6.33 & 7.86 & \\
$\mathrm{k}_{2}$ & 9.05 & 9.34 & 8.20 & \\
$\mathrm{k}_{2}$ & 7.79 & 8.48 & 8.09 & \\
$\mathrm{R}$ & 1.74 & 3.01 & 0.34 & \\
\hline
\end{tabular}

Table 5: Fitting equations with correlation coefficients for alcohol content

\begin{tabular}{llr}
\hline Model & Fitting equation & $\mathrm{R}^{2}$ \\
\hline Logistic & $y=4.0719-3.6534 / 1+(x / 31.735)^{3.2407}$ & 0.99925 \\
Boltzmann & $y=3.7524-3.5655 / 1+e^{x-29.6730 / 9.2836}$ & 0.99533 \\
\hline
\end{tabular}

y-Acid value, $\mathrm{g} / 100 \mathrm{~mL} ; \mathrm{x}$-Fermentation time, $\mathrm{h}$

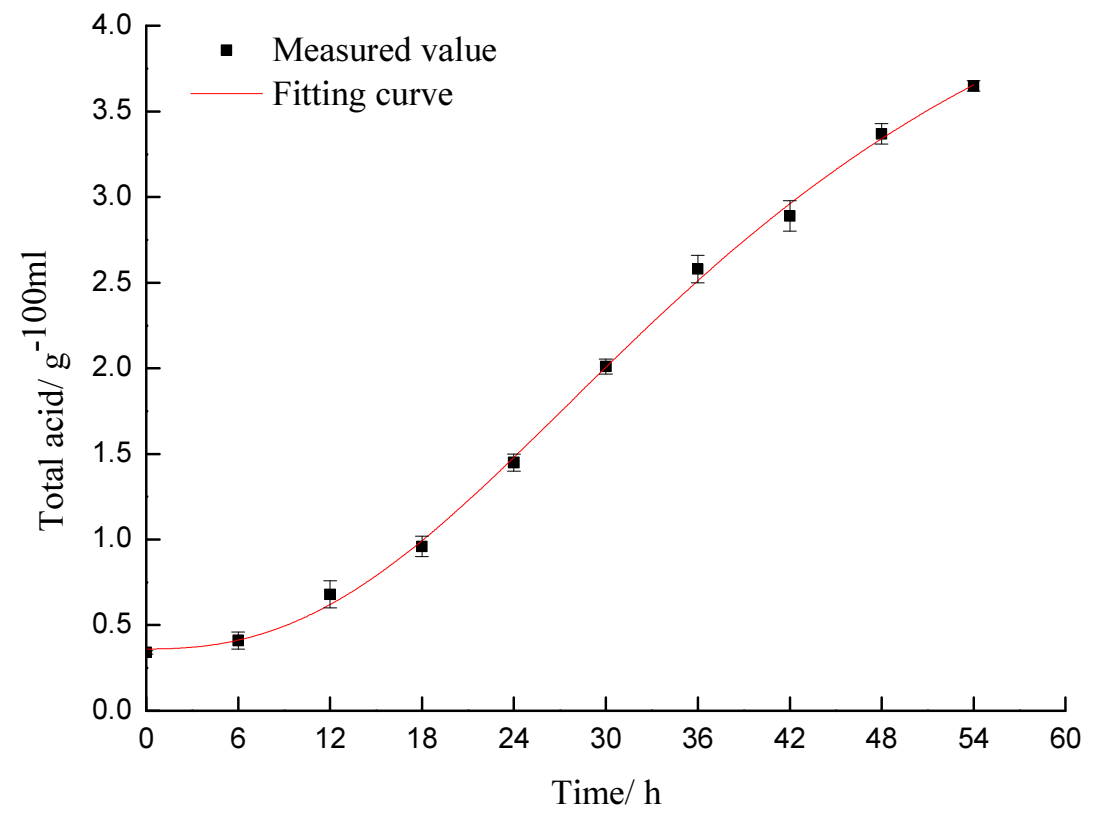

Fig. 3: Logistic fitting curve of aceit acid fermentation 


\section{Conclusion}

In this study, a fruit vinegar fermentation device that can be used conveniently at homes was designed. Apple was selected as experiment material to ferment. The parameters of alcohol fermentation and acetic acid fermentation were optimized through single-factor and orthogonal tests. The vinegar fermentation kinetic equation of apple vinegar was established and that explained the relationship between fermentation time and total acid content of apple vinegar. According to this equation, the fermentation device can produce different total acid content of apple vinegar by adjusting fermentation time automatically. It is available that users can make fruit vinegar with little fermentation knowledge. Compared with surface fermentation (Yanan et al., 2016; Chuyan et al, 2013), this fermentation process took less time to produce the same volume of fruit vinegar, saving almost $50 \mathrm{~h}$ from $100 \mathrm{~h}$ to $54 \mathrm{~h}$. Moreover, taking apple vinegar for example, the costing of fruit vinegar by using the device is $5 ¥ / \mathrm{L}$, which is cheaper than the same quality of fruit vinegar purchased from the market, almost $30 ¥$.

In recent years, studies of fruit vinegar beverages were increasingly paid attention to the diversity of fruit vinegar beverages, such as strawberry vinegar, persimmon vinegar and blueberry vinegar (Ubeda et al., 2016; Senji and Yuuya, 2008; MinSheng and Chien, 2010). However, these experiments were almost done in a triangular flask, which did not completely simulate the actual fermentation process. That could cause large errors in large-scale fermentation experiments (Hongzhang, 2013). In this study, all experiments were performed in the device with $2 \mathrm{~L}$ volume, which could generate less errors and more accurate results. The study was sufficient to provide reference and experience for further prevalent of fruit vinegar.

The specific parameters of this test were as follows: In alcohol fermentation, the fermentation time, fermentation temperature and bacteria amount were $72 \mathrm{~h}$, $30^{\circ} \mathrm{C}$ and $0.07 \%$, respectively. The verification test showed that the degree of alcohol in cider reached $7.8 \%$. In acetic acid fermentation, the fermentation temperature, ventilation and bacteria amount were $32^{\circ} \mathrm{C}$, $4 \mathrm{~L} / \mathrm{min}$ and $0.18 \%$, respectively. The verification test indicated that the total acid of apple vinegar reached 3.65 $\mathrm{g} / 100 \mathrm{~mL}$. The kinetic equation of acetic acid fermentation product was followed:

$$
y=4.0719-3.6534 / 1+(x / 31.735)^{3.2407}
$$

$y$-total acid value, $\mathrm{g} / 100 \mathrm{~mL} ; x$-Fermentation time, $\mathrm{h}$.

\section{Acknowledgment}

This work was supported by the Double First-rate Subject-Food Science and Engineering Program of Hebei Province (Project No. 2016SPGCA18) and the Program of Young and Top Talents of Hebei Province (Project No. HEBEI2013-17).

\section{Author's Contributions}

Xinpeng Dai and Xiaoxue Xing: Involved in sample preparation, study design, performing in the laboratory work and manuscript writing and revising and scientific discussion.

Lin Liu and Zhili Xu: Involved in manuscript writing.

Jianfeng Sun, Jie Wang and Jianlou Mu: Involved in study design and revising.

\section{Ethics}

The authors declare that they have no conflict of interest. All authors have read and approved the manuscript and no ethical issues involved.

\section{References}

Bouazza, A., A. Bitam, M. Amiali, A. Bounihi and L. Yargui et al., 2016. Effect of fruit vinegars on liver damage and oxidative stress in high-fat-fed rats. Pharmaceutical Biol., 54: 260-265.

DOI: $10.3109 / 13880209.2015 .1031910$

CIIN, 2016. Status analysis and development trend of china's apple vinegar industry. China Industry Information Network.

Chuyan, W., L. Yanwei, J. Junqiang, T.R. Sivakumarb and T. Fan et al., 2013. Optimization of fermentation process for preparation of mulberry fruit wine by response surface methodology. African J. Microbiol. Res., 7: 227-236.

DOI: $10.5897 / A J M R 12.2090$

Hongzhang, C., 2013. Modern Solid State Fermentation: Theory and Practice by Hongzhang Cheney. 1st Edn., ISBN-13: 978-7-122-16874-0.

Garrido-Vidal, D., C. Pizarro and M.G. José, 2003. Study of process variables in industrial acetic fermentation by a continuous pilot fermentor and response surfaces. Biotechnol. Progress, 19: 1468-1479. DOI: $10.1021 / \mathrm{bp} 034055 \mathrm{r}$

Gomez, J.M. and D. Cantero, 1998. Kinetics of substrate consumption and product formation in closed acetic fermentation systems. Bioprocess Eng., 18: 439-444. DOI: $10.1007 / \mathrm{s} 004490050468$

Gonzalez-Saiz, J.M. and C. Pizarro, 2003. Evaluation of kinetic models for industrial acetic fermentation: Proposal of a new model optimized by genetic algorithms. Biotechnol. Progress, 19: 599-611. DOI: $10.1021 / \mathrm{bp} 0256871$ 
Gullo, M., E. Verzelloni and M. Canonico, 2014. Aerobic submerged fermentation by acetic acid bacteria for vinegar production: Process and biotechnological aspects. Process Biochem., 49: 1571-1579. DOI: $10.1016 /$ j.procbio.2014.07.003

Infantes, D., A.G. Campo, J. Villaseñor and F.J. Fernández, 2012. Kinetic model and study of the influence of $\mathrm{pH}$, temperature and undissociated acids on acidogenic fermentation. Biochem. Eng. J., 66: 66-72. DOI: 10.1016/j.bej.2012.04.017

Jimenez-Hornero, J.E., I.M. Santos-Duenas and I. García-Garcíaet, 2009. Optimization of biotechnological processes. The acetic acid fermentation. Part III: Dynamic optimization. Biochem. Eng. J., 45: 22-29. DOI: $10.1016 /$ j.bej.2009.01.011

Jin, H., R. Liu and Y. He, 2015. Kinetic models and effects of initial total soluble sugar concentrations on batch ethanol fermentation of sweet sorghum stalk juice by Saccharomyces cerevisiae Strain. Energy Sources, 37: 1283-1290. DOI: $10.1080 / 15567036.2011 .616871$

Kocher, G.S., R. Singh and K.L. Kalra, 2007. Preparation of value added vinegar using apple juice. J. Food Sci. Technol., 44: 226-227.

Marques, F.P.P., W. Spinosa, K.F. Fernandeset, 2010. Quality pattern and identity of commercial fruit and vegetable vinegar (Acetic acid fermentation). Ciência e Tecnologia de Alimentos, 30: 119-126. DOI: $10.1590 / \mathrm{S} 0101-20612010000500019$

MinSheng, S. and P. Chien, 2010. Aroma impact components of rabbiteye blueberry (Vaccinium ashei) vinegars. Food Chem., 119: 923-928. DOI: $10.1016 /$ j.foodchem.2009.07.053.

Patzold, M., A. John and K.H. Bauer, 2005. Studies of selected components of apple and wine vinegars. Ernahrungs-umschau, 52: 265.

Pramanik, K., 2003. Parametric studies on batch alcohol fermentation using Saccharomyces yeast extracted from toddy. J. Chinese Inst. Chem. Eng., 34: 487-492.
Schmidt, F.R., 2005. Optimization and scale up of industrial fermentation processes. Applied Microbiol. Biotechnol., 68: 425-435.

DOI: $10.1007 / \mathrm{s} 00253-005-0003-0$

Senji, S. and I. Yuuya, 2008. Comparison of antioxidant properties of persimmon vinegar and some other commercial vinegars in radical-scavenging assays and on lipid oxidation tuna homogenates. Food Chem., 172: 739-744. DOI: 10.1016/j.foodchem.2007.08.080

Shahidi, F., J. McDonald and A. Chandrasekara, 2008. Phytochemicals of foods, beverages and fruit vinegars: Chemistry and health effects. Asia Pacific J. Clin. Nutrit., 17: 380-382.

Torija, M.J., N. Rozes, M. Poblet, J.M. Guillamón and A. Mas, 2003. Effects of fermentation temperature on the strain population of Saccharomyces cerevisiae. Int. J. Food Microbiol., 80: 47-53. DOI: $10.1016 / \mathrm{S} 0168-1605(02) 00144-7$

Ubeda, C., R. Callejón and A. Troncoso, 2016. A comparative study on aromatic profiles of strawberry vinegars obtained using different conditions in the production process. Food Chem., 192: 1051-9. DOI: 10.1016/j.foodchem.2015.07.091

Woo, J.M., K.M. Yang, S.U. Kim, L.M. Blank and J.B. Park, 2014. High temperature stimulates acetic acid accumulation and enhances the growth inhibition and ethanol production by Saccharomyces cerevisiae under fermenting conditions. Applied Microbiol. Biotechnol., 98: 6085-6094. DOI: $10.1007 / \mathrm{s} 00253-014-5691-\mathrm{x}$

Wu, R.N., P. Zhu, Y.H. Shang and Z. Qiuping, 2016. Optimization of lychee wine fermentation process using response surface methodology to reduce acetic acid content. Int. J. Agric. Biol. Eng., 9: 223-230. DOI: $10.3965 /$ j.ijabe.20160906.2270

Yanan, W., S. Qiu., Y. Wang and C. Jiang, 2016. Process optimization of acetic acid fermentation of hawthorn vinegar. Agric. Sci. Technol., 17: 420-423. DOI: 10.16175/j.cnki.1009-4229.2016.02.040 